\title{
Afidofauna associated with the decorative plants of Fabaceae family
}

\section{Afidofauna związana z roślinami ozdobnymi z rodziny Fabaceae}

\author{
Beata Borowiak-Sobkowiak ${ }^{1 *}$, Anna Paluszkiewicz ${ }^{2}$
}

\section{Summary}

Studies on afidofauna associated with decorative plants of the Fabaceae family were conducted at the Botanical Garden in Poznań in 2014-2015. This paper presents the species composition of aphids colonizing legumes and describes the degree of infestation of plants by these insects. The following eight monoecious species of aphids were identified from the collected samples: Aphis craccivora, Aphis cytisorum cytisorum, Aphis cytisorum sarothamni, Acyrthosiphon pisum, Acyrthosiphon caraganae caraganae, Megoura viciae, Appendiseta robiniae and Therioaphis tenera tenera. The aphids were found on 17 species of plants, including 7 species of herbaceous plants, 6 species of shrubs and 4 species of trees. A. craccivora was the species that occupied the most plants. The greatest damages were observed on Laburnum anagyroides caused by $A$. cytisorum cytisorum feeding. A. caraganae caraganae also formed large colonies on Colutea orientalis, A. cytisorum sarothamni on Sarothamnus scoparius, A. craccivora on Robinia and Caragana and M. viciae on Lathyrus latifolius and Vicia amoena.

Key words: aphids; decorative plants; Botanical Garden; Fabaceae

\section{Streszczenie}

Badania dotyczące afidofauny związanej z roślinami ozdobnymi z rodziny Fabaceae, prowadzono na terenie Ogrodu Botanicznego w Poznaniu w latach 2014-2015. W pracy przedstawiono skład gatunkowy mszyc zasiedlających rośliny bobowate oraz określono stopień zasiedlenia roślin przez te owady. Podczas prowadzonych badań stwierdzono 8 monoecyjnych gatunków mszyc: Aphis craccivora, Aphis cytisorum cytisorum, Aphis cytisorum sarothamni, Acyrthosiphon pisum, Acyrthosiphon caraganae caraganae, Megoura viciae, Appendiseta robiniae oraz Therioaphis tenera tenera. Mszyce notowano na 17 gatunkach roślin, w tym na 7 gatunkach roślin zielnych, na 6 gatunkach krzewów i na 4 gatunkach drzew. Gatunkiem, który zasiedlał najwięcej roślin był $A$. craccivora. Największe uszkodzenia obserwowano na Laburnum anagyroides pod wpływem żerowania $A$. cytisorum cytisorum. Duże kolonie tworzyły także A. caraganae caraganae na Colutea orientalis, A. cytisorum sarothamni na Sarothamnus scoparius, A. craccivora na robinii i karaganie, a także M. viciae na Lathyrus latifolius i Vicia amoena.

Słowa kluczowe: mszyce; rośliny ozdobne; Ogród Botaniczny; Fabaceae

\footnotetext{
Uniwersytet Przyrodniczy w Poznaniu

Katedra Entomologii i Ochrony Środowiska

Dąbrowskiego 159, 60-594 Poznań

${ }^{2}$ Osiedle Leśne 24, 62-028 Koziegłowy

*corresponding author: beata.borowiak@up.poznan.pl
} 


\section{Wstęp / Introduction}

Rośliny są nieodzownym elementem otoczenia każdego człowieka. Są szeroko wykorzystywane w założeniach zieleni miejskiej, wprowadzane do ogrodów przydomowych, na tarasy czy balkony. Tereny zielone pełnią wielorakie funkcje i wpływają pozytywnie na poprawę warunków życia mieszkańców. Działają korzystnie na klimat, wymianę powietrza, tłumienie hałasu, czy pochłanianie szkodliwych pyłów (Łukasiewicz i Łukasiewicz 2006). W kształtowaniu terenu zieleni stosuje się różne gatunki roślin, w tym charakteryzujące się oryginalnym wyglądem rośliny ozdobne.

Rośliny ozdobne okrytozalążkowe liczą na świecie 260 tys. gatunków, z czego około 20 tys. stanowią rośliny z rodziny Fabaceae (Czekalski 2010). W skład tej rodziny wchodzą rośliny zielne, krzewy, drzewa i pnącza. Wiele z nich ma duże znaczenie gospodarcze. Dzięki możliwości współżycia $\mathrm{z}$ bakteriami $\mathrm{z}$ rodzaju Rhizobium potrafią przyswajać wolny azot atmosferyczny, co umożliwia uprawy nawet na bardzo ubogich w ten pierwiastek glebach. Rośliny $\mathrm{z}$ rodziny Fabaceae często stosuje się jako tzw. zielone nawozy w celu użyźnienia gleby. Nie można zapominać także o bogatym źródle białka roślinnego. Wiele roślin $\mathrm{z}$ tej rodziny uprawianych jest także w ogrodach (Seneta i Dolatowski 2012). W Polsce ozdobne rośliny z rodziny bobowatych reprezentuje około 70 rodzajów. Większość $z$ nich to gatunki obce, najczęściej są to przedstawiciele krzewów oraz roślin zielnych.

Najliczniejszą grupą zasiedlającą roślinność w terenach zieleni miejskiej są owady o aparacie gębowym kłująco-ssącym. Przy postępującym uprzemysłowieniu i urbanizacji jednym z największych zagrożeń dla drzew i krzewów są mszyce (Trojan i Winiarska 2001; Barczak 2004). Ich żerowanie powoduje deformacje, obniża wartość dekoracyjną, hamuje wzrost i negatywnie wpływa na kondycję roślin (Berliński 1968).

Celem pracy było poznanie składu gatunkowego mszyc występujących na roślinach ozdobnych z rodziny Fabaceae, określenie terminu ich pojawu oraz stopnia zasiedlenia roślin.

\section{Materiały i metody / Materials and methods}

Badania nad występowaniem mszyc prowadzono na terenie Ogrodu Botanicznego Uniwersytetu im. Adama Mickiewicza w Poznaniu w latach 2014-2015. Jest to jedna z największych placówek dydaktyczno-naukowych pod względem kolekcji, gromadząca około 7 tys. gatunków i odmian roślin $z$ różnych stref klimatycznych. Zgromadzone są tu drzewa i krzewy stref klimatyczno-roślinnych świata, sukulenty, flora tropikalna, gatunki zagrożone wymarciem, czy byliny ozdobne. Lustrację roślin z rodziny Fabaceae na obecność mszyc, prowadzono dwa razy w miesiącu, od maja do października. Mszyce zbierano bezpośrednio $\mathrm{z}$ roślin i przechowywano w $75 \%$ alkoholu etylowym do czasu ich oznaczenia. W czasie lustracji określano także stopień zasiedlenia roślin przez mszyce, stosując pięciostopniową skalę, gdzie: I stopień - brak mszyc, II stopień - małe zasiedlenie (pojedyncze osobniki na roślinie), III stopień - średnie zasiedlenie (małe i średnie kolonie na organach rośliny, do 30 osobników w kolonii), IV stopień - duże zasiedlenie (duże kolonie na organach roślin, do 50 osobników w kolonii), V stopień bardzo duże zasiedlenie roślin (mszyce zasiedlają całą powierzchnię organów roślinnych).

W pracy przyjęto układ systematyczny i nazewnictwo mszyc za Wojciechowskim i wsp. (2015).

\section{Wyniki i dyskusja / Results and discussion}

W latach 2014-2015 w Ogrodzie Botanicznym na ozdobnych roślinach $\mathrm{z}$ rodziny Fabaceae, stwierdzono występowanie ośmiu gatunków mszyc. Były to: mszyca lucernowo-grochodrzewowa Aphis craccivora Koch, 1854, mszyca złotokapowa Aphis cytisorum cytisorum Hartig, 1841, Aphis cytisorum sarothamni Franssen, 1928, mszyca grochowa Acyrthosiphon pisum Harris, 1776, mszyca karaganowa Acyrthosiphon caraganae caraganae (Cholodovsky, 1907), mszyca wykowo-bobikowa Megoura viciae Buckton, 1876, zdobniczka robiniowa Appendiseta robiniae (Gillette, 1907) oraz Therioaphis tenera tenera (Aizenberg, 1956) (tab. 1, 2). Wszystkie te taksony to gatunki monoecyjne, przedstawiciele rodziny Aphididae. Sześć gatunków należy do podrodziny Aphidinae, z czego trzy gatunki do plemienia Aphidini i trzy do plemienia Macrosiphini. Natomiast dwa pozostałe gatunki wchodzą w skład podrodziny Calaphidinae i plemienia Panaphidini.

Spośród 37 gatunków roślin objętych lustracją, mszyce stwierdzono na 17, w tym na 7 gatunkach roślin zielnych, na 6 gatunkach krzewów i na 4 gatunkach drzew. Gatunkiem, który zasiedlał najwięcej roślin był $A$. craccivora. Notowany był zarówno na drzewach, krzewach i roślinach zielnych (tab. 1, 2). Występował od czerwca do sierpnia, tworząc największe kolonie na karaganie i robinii (tab. 2). A. craccivora wykazana była z Ogrodu Botanicznego w Poznaniu już wcześniej, w latach 2002-2003. Gatunek ten odławiano metodą pułapek Moerickego oraz zbierano metodą lustracji z Robinia pseudoacacia (Wilkaniec 2004). Mszyca ta stwierdzona była również na robinii, na terenie Arboretum Kórnickiego przez Ratajczak i Wilkaniec (2011), a także na Caragana frutex w terenach zieleni miejskiej w Bydgoszczy (Bennewicz i Barczak 2014). Powszechne występowanie tego gatunku jest wynikiem jego zdolności adaptacyjnych. A. craccivora przystosowuje się do zmiennych warunków środowiska, szczególnie do wysokich temperatur oraz roślin żywicielskich. Jego strategie przystosowawcze przejawiają się w morfologii, bionomii i behawiorze (Borowiak-Sobkowiak i wsp. 2017). Jest to gatunek pochodzący z cieplejszych rejonów świata, rozszerzający zarówno swój zasięg występowania, jak i spektrum roślin żywicielskich. Wprowadzanie do zieleni miejskiej roślin obcego pochodzenia umożliwia mu właśnie taką ekspansję.

Podczas prowadzonych obserwacji na roślinach zielnych z rodziny Fabaceae stwierdzono oprócz A. craccivora także $A$. pisum oraz $M$. viciae (tab. 2). Oba gatunki współwystępowały na Lathyrus latifolius, jednak mszyca wykowo-bobikowa tworzyła liczniejsze kolonie. Czwarty stopień zasiedlenia roślin przez ten gatunek obserwowano 
Tabela 1. Wykaz roślin w Ogrodzie Botanicznym w Poznaniu i stwierdzonych na nich gatunków mszyc

Table 1. List of plants in the Botanical Garden in Poznań and species of aphid identified on them

\begin{tabular}{|c|c|c|c|}
\hline $\begin{array}{l}\text { Podział } \\
\text { Division }\end{array}$ & $\begin{array}{l}\text { Gatunek rośliny } \\
\text { Plant species }\end{array}$ & $\begin{array}{l}\text { Gatunek mszycy wykazany w literaturze* } \\
\text { Aphid species reported in the literature }\end{array}$ & $\begin{array}{l}\text { Gatunek mszycy wykazany } \\
\text { w Ogrodzie Botanicznym } \\
\text { w latach 2014-2015 } \\
\text { Aphid species recorded } \\
\text { in the Botanical Garden } \\
\text { in the 2014-2015 }\end{array}$ \\
\hline \multirow{6}{*}{$\begin{array}{l}\text { Rośliny zielne } \\
\text { Herbal plants }\end{array}$} & $\begin{array}{l}\text { Astragalus arenarius L. } \\
\text { Astragalus ponticus Pall. }\end{array}$ & $\begin{array}{l}\text { Therioaphis (Pterocallidium) trifolii } \\
\text { ventromaculata F. M. Müller, } 1968 \\
\text { Aphis craccivora Koch, } 1854 \\
\text { Aphis tacita Huculak, } 1968\end{array}$ & $\begin{array}{l}- \\
+ \\
+\end{array}$ \\
\hline & Glycyrrhiza echinata L. & - & Megoura viciae Buckton, 1876 \\
\hline & $\begin{array}{l}\text { Lathyrus sp. } \\
\text { Lathyrus latifolius L. }\end{array}$ & $\begin{array}{l}\text { Acyrthosiphon pisum Harris, } 1776 \\
\text { Megoura viciae Buckton, } 1876 \\
\text { Megourella purpurea Hille Ris Lambers, } 1949\end{array}$ & $\begin{array}{l}+ \\
+ \\
-\end{array}$ \\
\hline & $\begin{array}{l}\text { Medicago sp. } \\
\text { Medicago sativa L. }\end{array}$ & $\begin{array}{l}\text { Therioaphis trifolii trifolii (Monell, 1882) } \\
\text { Acyrthosiphon pisum Harris, } 1776 \\
\text { Aphis coronillae Ferrari, } 1872 \\
\text { Aphis medicaginis Koch, } 1854\end{array}$ & $\begin{array}{c}- \\
+ \\
- \\
- \\
\text { Aphis craccivora Koch, } 1854\end{array}$ \\
\hline & $\begin{array}{l}\text { Vicia sp. } \\
\text { Vicia amoena Fisch. } \\
\text { Vicia unijuga A. Br. }\end{array}$ & $\begin{array}{l}\text { Aphis craccivora Koch, } 1854 \\
\text { Megoura viciae Buckton, } 1876 \\
\text { Acyrthosiphon pisum Harris, } 1776 \\
\text { Aphis craccae Linnaeus, } 1758 \\
\text { Rhopalosiphoninus } \\
\text { (Submegoura) heikinheimoi (Börner, 1952) } \\
\text { Myzus persicae (Sulzer, 1776) } \\
\text { Megourella tribulis (Walker, 1849) }\end{array}$ & $\begin{array}{l}+ \\
+ \\
+ \\
- \\
- \\
- \\
-\end{array}$ \\
\hline & $\begin{array}{l}\text { Hedysarum multijugum } \\
\text { Maxim. }\end{array}$ & - & Aphis craccivora Koch, 1854 \\
\hline \multirow{3}{*}{$\begin{array}{l}\text { Krzewy liściaste } \\
\text { Deciduous } \\
\text { shrubs }\end{array}$} & $\begin{array}{l}\text { Caragana arborescens Lam. } \\
\text { Caragana pygmaea (L.) DC. } \\
\text { Caragana maximowicziana } \\
\text { Kom. }\end{array}$ & $\begin{array}{l}\text { Therioaphis tenera tenera (Aizenberg, 1956) } \\
\text { Aphis craccivora Koch, } 1854 \\
\text { Acyrthosiphon pisum Harris, } 1776 \\
\text { Acyrthosiphon caraganae caraganae } \\
\text { (Cholodovsky, 1907) }\end{array}$ & $\begin{array}{l}+ \\
+ \\
- \\
+\end{array}$ \\
\hline & $\begin{array}{l}\text { Colutea arborescens L. } \\
\text { Colutea orientalis Mill. } \\
\text { Colutea brevialata Lange }\end{array}$ & - & $\begin{array}{l}\text { Aphis craccivora Koch, } 1854 \\
\text { Acyrthosiphon caraganae } \\
\text { caraganae (Cholodovsky, 1907) }\end{array}$ \\
\hline & Sarothamnus scoparius (L.) & $\begin{array}{l}\text { Ctenocallis setosus (Kaltenbach, 1846) } \\
\text { Aphis cytisorum sarothamni Franssen, } 1928 \\
\text { Acyrthosiphon parvum Börner, } 1950\end{array}$ & $\begin{array}{l}- \\
+ \\
+\end{array}$ \\
\hline & Laburnum anagyroides Medik. & Aphis cytisorum cytisorum Hartig, 1841 & + \\
\hline $\begin{array}{l}\text { Drzewa liściaste } \\
\text { Deciduous trees }\end{array}$ & $\begin{array}{l}\text { Robinia pseudoacacia } \\
\text { 'Karolina Zamoyska' } \\
\text { Robinia elliottii (Champ.) } \\
\text { Robinia pseudoacacia L. }\end{array}$ & $\begin{array}{l}\text { Aphis craccivora Koch, } 1854 \\
\text { Acyrthosiphon pisum Harris, } 1776\end{array}$ & $\begin{array}{l}\qquad+ \\
\qquad \\
\text { Appendiseta robiniae (Gillette, } \\
1907)\end{array}$ \\
\hline
\end{tabular}

*według Szelęgiewicza 1968 oraz Osiadacz i Hałaj 2010 - according to Szelęgiewicz 1968 and Osiadacz and Hałaj 2010 
Tabela 2. Termin występowania i stopień zasiedlenia roślin przez mszyce w Ogrodzie Botanicznym w latach 2014-2015 Table 2. Term of occurrence and degree of plants infestation by aphids in the Botanical Garden in the 2014-2015

\begin{tabular}{|c|c|c|c|}
\hline $\begin{array}{l}\text { Gatunek } \\
\text { Species }\end{array}$ & $\begin{array}{l}\text { Roślina żywicielska } \\
\text { Host plant }\end{array}$ & $\begin{array}{l}\text { Miesiące występowania } \\
\text { Months of occurrence }\end{array}$ & $\begin{array}{c}\text { Stopień } \\
\text { zasiedlenia* } \\
\text { Degree } \\
\text { of infestation }\end{array}$ \\
\hline $\begin{array}{l}\text { Acyrthosiphon caraganae caraganae } \\
\text { (Cholodovsky, 1907) }\end{array}$ & $\begin{array}{l}\text { Caragana arborescens Lam. } \\
\text { Caragana pygmaea (L.) DC. } \\
\text { Colutea arborescens L. } \\
\text { Colutea orientalis Mill. }\end{array}$ & $\begin{array}{l}\mathrm{V}-\mathrm{VII} \\
\mathrm{V}-\mathrm{VII} \\
\mathrm{V}-\mathrm{VII} \\
\mathrm{V}-\mathrm{VI}\end{array}$ & $\begin{array}{l}\text { II-III } \\
\text { II-III } \\
\text { II-III } \\
\text { III-IV }\end{array}$ \\
\hline Acyrthosiphon pisum Harris, 1776 & $\begin{array}{l}\text { Lathyrus latifolius L. } \\
\text { Medicago sativa L. } \\
\text { Vicia sp. }\end{array}$ & $\begin{array}{l}\text { VII-VIII } \\
\text { VI-VIII } \\
\text { VII-VIII }\end{array}$ & $\begin{array}{l}\text { II-III } \\
\text { II-III } \\
\text { III }\end{array}$ \\
\hline Aphis cytisorum cytisorum Hartig, 1841 & Laburnum anagyroides Medik. & VI-VIII & $\mathrm{II}-\mathrm{V}$ \\
\hline Aphis cytisorum sarothamni Franssen, 1928 & Sarothamnus scoparius (L.) & VI-VIII & II-IV \\
\hline Aphis craccivora Koch, 1854 & $\begin{array}{l}\text { Caragana maximowicziana Kom. } \\
\text { Caragana pygmaea (L.) DC. } \\
\text { Robinia pseudoacacia } \\
\text { 'Karolina Zamoyska' } \\
\text { Robinia pseudoacacia L. } \\
\text { Medicago sativa L. } \\
\text { Colutea arborescens L. } \\
\text { Hedysarum multijugum Maxim. } \\
\text { Astragalus arenarius L. } \\
\text { Vicia sp. }\end{array}$ & $\begin{array}{c}\text { VI-VII } \\
\text { VI } \\
\text { VI-VII } \\
\text { VI-VIII } \\
\text { VII-VIII } \\
\text { VII } \\
\text { VI-VII } \\
\text { VI-VII } \\
\text { VI-VII }\end{array}$ & $\begin{array}{l}\text { II-IV } \\
\text { IV } \\
\text { II-III } \\
\text { II-IV } \\
\text { II-III } \\
\text { III } \\
\text { II-III } \\
\text { II-III } \\
\text { II-III }\end{array}$ \\
\hline Appendiseta robiniae (Gillette, 1907) & $\begin{array}{l}\text { Robinia elliottii (Champ.) } \\
\text { Robinia pseudoacacia } \\
\text { 'Karolina Zamoyska' } \\
\text { Robinia pseudoacacia L. }\end{array}$ & $\begin{array}{l}\text { VI-VII } \\
\text { VI-VII } \\
\text { VI-VIII }\end{array}$ & $\begin{array}{l}\text { II-III } \\
\text { II-III } \\
\text { II-III }\end{array}$ \\
\hline Megoura viciae Buckton, 1876 & $\begin{array}{l}\text { Glycyrrhiza echinata L. } \\
\text { Lathyrus latifolius L. } \\
\text { Vicia amoena Fisch. }\end{array}$ & $\begin{array}{c}\text { IX-X } \\
\text { VII-VIII } \\
\text { V-VI }\end{array}$ & $\begin{array}{l}\text { II-III } \\
\text { II-IV } \\
\text { III-IV }\end{array}$ \\
\hline $\begin{array}{l}\text { Therioaphis tenera tenera } \\
\text { (Aizenberg, 1956) }\end{array}$ & Caragana arborescens Lam. & VIII-IX & II \\
\hline
\end{tabular}

*I - brak mszyc, II - małe zasiedlenie (pojedyncze osobniki na roślinie), III - średnie zasiedlenie (małe i średnie kolonie na organach rośliny, do 30 osobników w kolonii), IV - duże zasiedlenie (duże kolonie na organach roślin, do 50 osobników w kolonii), V - bardzo duże zasiedlenie roślin (mszyce zasiedlają całą powierzchnię organów roślinnych)

I - no aphids, II - few aphids (single specimens of plants), III - average intensity (small and medium colonies on plants organs, up to 30 specimens/colony), IV - large intensity (large colonies on plants organs, up to 50 specimens/colony), V - very large intensity (aphids cover the surface of entire plant parts)

także na Vicia amoena w drugiej dekadzie czerwca. Natomiast najdłużej w sezonie występowanie tego gatunku notowano na Glycyrrhiza echinata (tab. 2). Wśród 107 gatunków mszyc stwierdzonych w Ogrodzie Botanicznym w latach 2002-2003, zaledwie 20 taksonów rozwijało się na roślinach zielnych (Wilkaniec 2004). Do gatunków tych należały także $A$. pisum i $M$. viciae.

Jednym z głównych czynników wpływających na rozwój owadów jest temperatura, która istotnie wpływa także na kondycję roślin żywicielskich. Mszyce należą do organizmów plastycznych ekologicznie, są wskaźnikami zmian klimatu i wykazują szybką reakcję na zmiany środowiskowe (Dixon 1998; Hulle i wsp. 2010; Ruszkowska i Strażyński 2011). Rośliny ozdobne często nie mają odpowiednich warunków do wzrostu i rozwoju. Złe warunki ekologiczne zwiększają podatność roślin na choroby i zasiedlenie przez szkodniki. Coraz częściej na roślinach ozdobnych występują mszyce. Ich żerowanie obniża wartość dekoracyjną, prowadzi do zahamowania wzrostu, odbarwienia, kędzierzawienia liści, czy powstawania narośli i deformacji (Berliński 1968). W latach 2014-2015 podczas prowadzonych obserwacji, największe uszkodzenia obserwowano na krzewach Sarothamnus scoparius powodowane przez A. cytisorum sarothamni, a na drzewach na Laburnum anagyroides pod wpływem żerowania A. cytisorum cytisorum. Także wiosną obserwowano silne zasiedlenie krzewów Colutea orientalis przez A. caraganae caraganae (tab. 2). Obniżenie wartości dekoracyjnych na złotokapie i na żarnowcu obserwowała także w Ogrodzie Botanicznym Wilkaniec (2004). Autorka notowała wysoki stopień zasiedlenia tych roślin przez mszyce. 
$\mathrm{Na}$ świecie wciąż opisywane są nowe dla nauki gatunki mszyc. W większości jednak są to opisy dokonane na podstawie materiału z kolekcji muzealnych, czy naukowych (Hałaj i Osiadacz 2016). Natomiast materiał zebrany podczas badań terenowych w mniejszym stopniu pozwala na odkrycie nowych taksonów, informuje jednak o poszerzeniu zasięgu występowania gatunków obcych w faunie danego kraju. Takim gatunkiem potwierdzonym w 2007 roku w Polsce jest A. robiniae (Borowiak-Sobkowiak i wsp. 2008). Zdobniczka robiniowa jest gatunkiem holocyklicznym, jednodomnym i monofagiem żerującym na $R$. pseudoacacia. Gatunek ten bardzo dobrze zaaklimatyzował się w Polsce, a jego predyspozycje biologiczne umożliwią mu szybkie poszerzanie swego zasięgu (Borowiak-Sobkowiak i Durak 2012). Podczas prowadzonych badań $A$. robiniae również notowana była na robinii, tworząc małe lub średniej wielkości kolonie na liściach (tab. 2). Jej obecność stwierdzono także w Arboretum Kórnickim (Ratajczak i Wilkaniec 2011).

Mszyce stanowią jedną z najliczniejszych grup zasiedlającą zieleń miejską. W ostatnich latach ukazało się w Polsce kilka prac omawiających afidofaunę parków, ogrodów botanicznych, czy dendrologicznych. Stan badań dotyczący tej tematyki jest jednak nadal niedostateczny, stąd celowe jest prowadzenie dalszych obserwacji.

\section{Wnioski / Conclusions}

1. Zasiedlenie przez mszyce wielu gatunków i odmian roślin obcego pochodzenia świadczy o dużych możliwościach adaptacyjnych krajowej afidofauny.

2. Na roślinach ozdobnych $\mathrm{z}$ rodziny Fabaceae stwierdzono występowanie 8 gatunków mszyc: na 7 gatunkach roślin zielnych, na 6 gatunkach krzewów i na 4 gatunkach drzew.

3. A. craccivora jest gatunkiem zasiedlającym najwięcej roślin, co świadczy o jego dużych zdolnościach adaptacyjnych do zmiennych warunków środowiskowych i do roślin żywicielskich.

\section{Literatura / References}

Barczak T. 2004. Niektóre aspekty bionomii i ekologii mszycy przerostek skrętnik, Pemphigus spirothecae Pass. (Homoptera: Pemphigidae) w środowisku miejskim. s. 235-255. W: „Fauna miast Europy Środkowej 21. wieku” (T. Barczak, P. Indykiewicz, red.). LOGO, Bydgoszcz, 584 ss.

Bennewicz J., Barczak T. 2014. Mszyce środowisk zurbanizowanych. s. 65-75. W: „Urban Fauna. Animal, Man, and the City Interactions and Relationships” (P. Indykiewicz, J. Böhner, red.). ArtStudio, Bydgoszcz, 397 ss.

Berliński K. 1968. Znaczenie gospodarcze mszyc. s. 171-183. W: „Kurs afidologii ogólnej”. PAN, Wrocław-Warszawa-Kraków Zakład Narodowy im. Ossolińskich.

Borowiak-Sobkowiak B., Durak R. 2012. Biology and ecology of Appendiseta robiniae (Hemiptera: Aphidoidea) - an alien species in Europe. Central European Journal of Biology 7 (3): 487-494. DOI: 10.2478/s11535-012-0034-3.

Borowiak-Sobkowiak B., Durak R., Wilkaniec B. 2008. Appendiseta robiniae (Gilette), 1907 (Hemiptera, Aphidoidea) - an aphids species new to Poland. Polish Journal of Entomology 77 (1): 5-9.

Borowiak-Sobkowiak B., Durak R., Wilkaniec B. 2017. Morphology, biology and behavioral aspects of Aphis craccivora (Hemiptera: Aphididae) on Robinia pseudoacacia. Acta Scientiarum Polonorum, Hortorum Cultus 16 (1): 39-49.

Czekalski M. 2010. Ogólna uprawa roślin ozdobnych. Wydawnictwo Uniwersytetu Przyrodniczego we Wrocławiu, Warszawa, s. 13-15, 242 ss.

Dixon A.F.G. 1998. Aphid Ecology: an Optimization Approach. Chapman and Hall, London, 312 pp.

Hałaj R., Osiadacz B. 2016. Klucze do oznaczania owadów Polski / Keys for the Identification of Polish Aphids. Część / Part XVII Hemiptera [Homoptera]. Zeszyt / Issue 5c. Mszyce / Aphids - Aphidomorpha Mszyce właściwe - Aphidoidea Hormaphididae, Mindaridae, Phloeomyzidae, Thelaxidae. Polskie Towarzystwo Entomologiczne / Polish Entomological Society, Nr 179 serii kluczy / No 179 in the key series, Wrocław, 164 pp. ISBN 978-83-61764-55-7.

Hulle M., d'Acier A.C., Bankhead-Dronnet S., Harrington R. 2010. Aphids in the face of global changes. C. R. Biologies 333: $497-503$.

Łukasiewicz A., Łukasiewicz Sz. 2006. Rola i kształtowanie zieleni miejskiej. Wydawnictwo Naukowe UAM, Poznań, 128 ss.

Ratajczak J., Wilkaniec B. 2011. Fauna mszyc (Hemiptera: Aphidoidea, Phylloxeroidea) w Arboretum Kórnickim (Wielkopolska). Wiadomości Entomologiczne 30 (1): 17-26.

Ruszkowska M., Strażyński P. 2011. Elementy zmian w bionomii mszyc dendrofilnych w środowisku zurbanizowanym. Zeszyty Problemowe Postępów Nauk Rolniczych 562: 221-227.

Seneta W., Dolatowski J. 2012. Dendrologia. Wydawnictwo Naukowe PWN, Warszawa, s. 299-328, 544 ss.

Trojan P., Winiarska G. 2001. Miasto jako archipelag wysp śródlądowych. s. 10-16. W: „Bioróżnorodność i ekologia populacji zwierzęcych w środowiskach zurbanizowanych" (P. Indykiewicz, T. Barczak, G. Kaczorowski, red.). NICE, Bydgoszcz, 297 ss.

Wilkaniec B. 2004. Afidofauna Ogrodu Botanicznego w Poznaniu. s. 167-177. W: „Fauna miast Europy Środkowej 21. wieku” (T. Barczak, P. Indykiewicz, red.). LOGO, Bydgoszcz, 584 ss.

Wojciechowski W., Depa Ł., Kanturski M., Wegierek P., Wieczorek K. 2015. An annotated checklist of the Aphids (Hemiptera: Aphidomorpha) of Poland. Polish Journal of Entomology 84 (4): 383-420. DOI: 10.1515/pjen-2015-0033. 